ISSN: 2162-3104 Print/ ISSN: 2166-3750 Online

Volume 8, Issue 3 (2018), pp. 1422-1439

(C) Journal of International Students

http://jistudents.org/

doi: $10.5281 /$ zenodo. 1254605

\title{
Critical Intercultural Practice: Learning in and for a Multicultural Globalizing World
}

\author{
David Killick \\ Leeds Beckett University, UK
}

\begin{abstract}
Universities fail to offer equitable learning experiences for their diverse students. At the same time, the value of diverse student identities and perspectives remains largely unrealized. In a globalising higher education context, these issues are exacerbated while the post-national university is increasingly complicit in advancing the neoliberal project and neglecting its potential to enable its diverse students to enhance social justice locally and globally. Although much current practice in outcomes-based higher education contributes to each of these processes, its underpinning theories of learning and its design features are compatible with more expansive and inclusive aspirations. Drawing upon critical and culturally relevant pedagogies, this article presents principles for the development of "critical intercultural practice" to empower all students in and for a multicultural globalizing world.
\end{abstract}

Keywords: critical pedagogy, culturally relevant pedagogy, diversity, internationalization

As Anglophone western universities (AWUs) expand their influence among increasingly diverse global stakeholders through the full range of their internationalization activities (de Wit et al., 2017; Knight, 2016; Marginson, 2007), there is a tightening of the tensions concerning their role and purpose in the world. In particular, AWUs have contributed to the ascendancy of the neoliberal agenda for employability (capabilities to meet the demands of the labor market) at the expense of education for (global) social justice (capabilities to contribute to the advance of a more equitable global society). While the ascendency of neoliberalism is not restricted to Anglophone 
western countries, they are among its most powerful advocates, and as many AWUs expand their global engagement, they are simultaneously exporting the neoliberal project into the international spaces in which they operate and from which their students are drawn. The students within these emerging "post-national universities" (Killick, 2017) come from highly diverse societies and cultures, many of which are not equal beneficiaries of, or contributors to, the spread of global capitalism. They are also individually diverse, entering and experiencing university with differential privilege and disadvantage, and with potentially highly valuable diverse understandings and experiences of the world.

All universities have responsibilities to strive to achieve equitable outcomes for all their students and to develop graduates who can make their way in a multicultural and globalizing world, but the post-national AWU must do so for complexly diverse stakeholders. This article proposes an approach to practice which has the potential to support that work and to reassert the role of higher education as a contributor to the advance of social justice, locally and globally.

\section{STUDENT DIVERSITY AND MULTICULTURAL GLOBALIZING HIGHER EDUCATION}

It is well-documented that universities in many countries fail to provide their domestic students from across diverse minority groups with relevant and inclusive learning experiences (Ancis et al., 2000; Bailey, 2016; Bourke, 2010; ECU, 2009; Gilardi \& Guglielmetti, 2011; NUS, 2011) and thereby deny them equitable academic and employability outcomes (Berry \& Loke, 2011; ECU, 2014; HEFCE, 2015; NCES, 2010; Stevenson, 2012; Turner, 2013). At the same time, international students within AWUs are often identified as being challenged by poor English language skills and/or a lack of familiarity with the educational norms and rituals of their host university (e.g., how "collusion" differs from "collaboration" or how students are expected to enact group work). As with other minority groups, this kind of "deficit modelling" of international students (Leask, 2009; Smit, 2012) serves to perpetuate stereotypes which then potentially exacerbate unconscious biases in academic judgements (ECU, 2013; Malouff et al., 2014). The limited focus within this deficit modelling process also serves to mask other potentially disadvantaging dimensions of student diversity. Although rarely acknowledged, international students belong to and identify with as full a range of minorities as their domestic student peers, and so many are likely to be similarly ill-served by their university learning and teaching experiences. We can be sure that some, for example, belong to 
ethnic minorities, some have specific learning needs, some are female, and some identify as belonging to the LGBTQA community (while some remain terrified to do so).

Intersectionality research (Crenshaw, 1991) identifies how multiple dimensions of structural disadvantage, such as being Black and being female, multiply the challenges faced by individuals in terms of their educational and wider social successes. Even within local AWU contexts, neglected aspects of diversity, such as the differences within and across minority immigrant and indigenous populations, demands fuller recognition and an expanded conceptualization of diversity and disadvantage (Mukherji et al., 2017). More widely, as post-national universities expand their global footprints through the complex gamut of operations under the transnational education (TNE) umbrella (ACE, 2015; Knight, 2016), they must also work to gain sophisticated understandings of their complexly diverse international student bodies. Whether they are studying on branch campuses, online, at partner institutions, or on an institution's home campus, data on international student diversity tends to be poorly captured, if at all (James, 2012). Thus, administrators and academics alike have limited understanding of the specific intersecting structural inequalities (e.g., ethnicity plus sexuality plus gender) which may advantage or disadvantage individual students across the local and global contexts in which their university is operating, or from which their students are drawn. In such circumstances, the provision of equitable and empowering learning experiences for minority domestic and international students becomes increasingly problematic. Exporting practice which is failing many at home is unlikely to achieve better outcomes elsewhere.

At the same time, student diversity is projected to be a positive stimulus for learning. Exploring a subject among students of diverse ethnicities, genders, nationalities, and so forth is touted as a means to engage with alternative perspectives, and it has been shown to develop critical thinking, civic mindedness, openness, and other learning gains (Cole \& Zhou, 2014; Crisp \& Turner, 2011; Curşeu \& Pluut, 2011; Denson \& Bowman, 2013; Denson \& Zhang, 2010; Lewis et al., 2012; Loes et al., 2012). Within the internationalization literature, however, the greatest focus appears to be on the potential learning gain for domestic students, while studies of the benefits of multicultural diversity more generally are "often focused on the experiences of White students, their experiences with Black students, and any subsequent impact on learning and/or development" (Bourke, 2010, p. 127). Despite the claimed learning gain advantages, the majority of domestic students appear resistant to finding their "international" or "multicultural" course-mates sufficiently interesting to 
make the efforts needed to interact with them or learn from them (Fozdar \& Volet, 2016; Volet \& Ang, 2012). This should not surprise us; students, like all human beings, are reluctant to move out of the comforts of their ingroups, their established communities of similitude, in which they have developed and can retain their social identities (Tajfel \& Turner, 1986). Despite commonplace assertions that we live in increasingly diverse societies, meaningful encounters with people who are different to ourselves may not be commonplace at all. The demographics of the communities which are home to the vast majority of domestic AWU students are arguably experiencing greater social segregation, as widening wealth distribution gaps, for example, turn whole neighborhoods into no-can-go areas for any but the middle classes, while a growth in anti-immigrant and Islamaphobic attitudes are fracturing already fragile multicultural experiences. Many of the societies from which AWU international students are drawn are not at all ethnically diverse or religiously plural. In reality, moving among, let alone across, dimensions of diversity is not something with which many students have much prior experience. If students are to develop capabilities in this area, approaches to learning and teaching need to be designed that will build, reward, and assess those capabilities.

The lived experience of diversity among AWU students at home and overseas, then, appears to be one of being undervalued and ill-served by current learning and teaching practice and the attitudes and behaviors of their peers. Practice which sets out to overcome these limitations is needed if higher education is to address these challenges and realize the potential learning gains of the increasingly diverse student body brought by internationalization and widening participation.

\section{LEARNING AND MULTICULTURAL GLOBALIZING HIGHER EDUCATION}

Although the social classification of people into groups is a part of what it is to be human, this does not mean that students cannot transcend the limitations of group membership. Groups are "real if people think they are: they then behave in ways that assume that groups are real and, in so doing, construct that reality. They realise it" (Jenkins, 2014, p. 13). Education is a deliberate intervention in people's lives intended to enable students to realize themselves and aspects of the world in ways which would not have been possible without it. The post-national university, with its expanded range of student diversity and global stakeholders, is positioned to develop approaches to practice designed to enable all of its students to realize a more inclusive sense of others and a more expansive sense of self. However, 
given many students' inexperience of meaningful cross-cultural interaction, and their apparent inability or unwillingness to act inclusively towards their peers, building their capabilities to engage with diverse others and perspectives requires designing learning experiences which develop and reward boundary crossing. At the same time, overcoming inequities in the learning experiences of minority domestic or international students requires deliberate "act[s] of inclusion" (Winkle-Wagner \& Locks, 2014, p. 3). These are complementary objectives, which are compatible with theories of learning familiar within the AWU.

Social and constructivist learning theories (Bandura, 1977; Vygotsky, 1978), which underpin dominant best practice models in AWUs, emphasize that students construct their learning among social others. Among the core assumptions surrounding student-centered learning theories are the necessity of "access to multiple perspectives, resources, and representations" (Land et al., 2012, p. 8), and of building communities of practice within which successful learning can be situated (Lave \& Wenger, 1998). However, social learning is a complex reciprocal process which can lead to a modelling of selected peers and their communities or cultures which is more accepting and inclusive, or less so. Participant equality is a key contributor to prejudice reduction within encounters with others (Allport, 1979 [1954]; Pettigrew \& Tropp, 2008). Learning experiences which are not designed to build equitable mutual engagement across differences - real or perceived - risk maintaining or enhancing established, socialized fears, distrusts, and dislikes of "Others." They also, in the same process, reduce the need and opportunity for the development of critical thinking about established ideas and ways of being. For students from majority groups, such learning experiences constitute a form of "banking" education (Freire, 1970), in which their established worldviews are reinforced; for minority-group students, they risk being alienating and disempowering. In a similar vein, work upon the internationalization of the curriculum (IOC) has identified that access to international content or global perspectives can itself be characterized by "add-on" approaches (Bond, 2003), which retain all the fundamentals of the original curriculum, adding largely spurious content which students continue to engage with from majority ("domestic") perspectives, and continue to be assessed on the basis of their capabilities to replicate those perspectives. By contrast, a "transformation" approach seeks to enable the kind of perspective transformation embedded within transformative learning theory (Mezirow, 1995). However, where a student's learning experiences continue to be circumscribed by differential power dynamics across diverse peers and academics (and countries and continents), there remains the danger that the 
greatest transformation requirements fall to minority students. While this offers the greatest learning gain to those students, it may do so at the cost of their cultural integrity/identity and require them to jump higher hurdles in order to achieve as well as their majority peers.

Within AWUs, assessment has long been recognized to be a significant driver of student behavior and learning (Brown, 2005; Knight, 1995). In a constructively aligned program of study (Biggs, 2003), what is assessed, how it is assessed, and what elements of performance are rewarded are determined by the learning outcomes of the unit of study (module, course, etc.). Enabling students to achieve and evidence those learning outcomes through their assessments determines how learning experiences are structured. While outcomes-based curriculum design has often been harnessed to the neoliberal project, it can also serve to deliver more equitable and empowering education for a multicultural globalizing world. Within the outcomes-based paradigm, enabling students to make shifts in how they (1) envision and interact with the full range of their diverse peers, (2) engage with alternative perspectives and priorities within their discipline, (3) interact with diverse others locally and globally, and (4) are enabled to take actions in and for a multicultural and globalizing world may be achieved by deliberate and sustainable structural action to build disciplinary learning outcomes, experiences, environments, and assessments which develop and reward their capabilities to do so.

Several universities have sought to introduce graduate attributes which encompass relevant skill-sets as a mechanism to achieve some of these (or similar). In the main, such attributes have been presented as representing the skill-sets of all students of a particular university. However, limited work seems to have been done within those universities to embed such attributes within mainstream programs of study, or measure the degree to which a particular university's students can actually evidence them by graduation. Unusually, one university project has sought to embed its graduate attributes across disciplinary learning outcomes (Jones \& Killick, 2013), but the degree to which it has succeeded has yet to be researched.

Generic graduate attributes, then, are almost inevitably at some remove from a student's chosen discipline. They are also created and interpreted within those same academic traditions which are demonstrably failing many minority students, and which are simultaneously being subverted to achieving outcomes which reflect the marketization values of neoliberalism. Both of these trends are increasingly less tenable as higher education institutions work with diverse students in different international contexts, and widen participation at home to larger numbers of nontraditional and otherwise-diverse students. The advance of the post-national 
university, when characterized by the export of an educational philosophy and curriculum designed to enable a majority domestic group to succeed in ways valorized by the local marketplace, risks becoming a colonizing venture which disregards, disrespects, and dismantles local and minority group ontologies, epistemologies, and identities. Apart from the violence that such education commits against individuals and their cultures, it also negates the potential learning advantages being created through the widening of student diversity and the contexts within which learning is taking place and might be applied.

\section{CRITICAL AND CULTURALLY RELEVANT PEDAGOGIES}

Although the potential benefits of bringing together insights and agendas from internationalization of the curriculum and diversity education have been noted for some time (Caruana \& Ploner, 2010; ECU, 2011; Olson et al., 2007), little has been achieved in terms of policy or practice. In a similar vein, international educators have rarely articulated their aspirations within a critical pedagogy frame, yet the ethos surrounding intercultural/global learning has important synergies with critical pedagogy and culturally relevant pedagogy when seen within a global context. Fundamentals of critical and culturally relevant pedagogies are briefly noted in this section as they underpin the proposals for critical intercultural practice below.

A "complex critical pedagogy" for the twenty-first century frames education as a process of transformation through which students develop a "critical consciousness" that empowers them to take social action, while appreciating the "fact that all educational spaces are unique and politically contested" (Kincheloe, 2012, p. 155). A critical consciousness requires challenging established interpretations of the world, understanding forms and sources of power and oppression, and recognizing the consequences of the decisions/actions of one's self and others. For Freire (1974), this process begins with the recognition that the socio-cultural world is a created world which is, therefore, open to challenge and change. It is also a world which begs "the wisdom of being able to live with what is different, so as to be able to fight the common enemy" (Freire \& Faundez, 1989, p. 18; cited in McArthur, 2010, p. 497). Developments within the post-national university, as noted, complicate already complex questions of equity and empowerment across student diversity, and so it is also relevant that critical pedagogy recognizes that the experiences and forms of oppression of marginalized people "vary across time and space" (Edwards Jr, 2010, p. 228), and critical pedagogy itself "has much to learn from the often subjugated knowledges of African, African American, Asian, and indigenous peoples" (Kincheloe, 
2012, p. 149). Equitable and relevant practice within the post-national university must recognize and seek to surface subjugated knowledges across its stakeholders and their societies, and seek to reform wherever institutions or practice may be complicit in further subjugation. In all of this, critical pedagogy situates the academic practitioner as a "self-reflective educator who is more than the instrument of a safely approved and officially sanctioned worldview" (Giroux, 2006, p. 33).

Culturally relevant pedagogy (CRP) developed in the contexts of multicultural education in the United States (Ladson-Billings, 1995a, 1995b). CRP is founded upon three principles (Ladson-Billings, 1995a, p. 160):

- Students must experience academic success.

- Students must develop and/or maintain their cultural competence.

- Students must develop a critical consciousness through which they challenge the status quo of the current social order.

CRP learning environments are designed to be inclusive, which means helping students to value and understand their own cultures and the "cultures of their peers" (Byrd, 2016, p. 2). CRP and its allied approaches are also committed to "collective empowerment and social justice" (Aronson \& Laughter, 2016, p. 164), and CRP educators "acknowledge and honor the diverse viewpoints of their student population and refrain from promoting homogeneous perspectives as universal beliefs" (Oran, 2009, n.p.). Becoming an effective CRP practitioner requires the deconstruction and reformation of some "longstanding pedagogical assumptions, beliefs, and practices" (Gay, 2000, p. 203).

Ladson Billings differentiates CRP from critical pedagogy by virtue of it being "specifically committed to collective, not merely individual, empowerment" (1995a, p. 160). I suggest that this distinction is not now sustainable in a globalizing world in which students of multiple disadvantaged groups, each potentially carrying multiple intersecting individual identities, collectively study programs with common curricula across diverse global contexts. A program which advances the empowerment of Black students in the United States is legitimate, but only insofar as it similarly advances the empowerment of its LGBTQA students in Malaysia, and its female students in the United Arab Emirates (for example), and, indeed, of its White LGBTQA students in the U.S. A critical, culturally relevant pedagogy for a multicultural globalizing world necessarily focuses on individual empowerment for engaging in collective, intercultural, social action within and beyond an individual's group(s) by 
requiring, for example, that Black students in the U.S. recognize how they, too, may be complicit in the subjugation of indigenous peoples at home and of exploited labor overseas.

\section{CRITICAL INTERCULTURAL PRACTICE}

To combat the marginalization of minority students, to build capabilities to see oneself and others in more inclusive ways, and to develop agency to take action in a multicultural globalizing world, critical intercultural practice (CIP) sets out to engage students' cultural identities and experiences through the critical exploration of diverse perspectives among diverse others. CIP is proposed as a set of emergent principles upon which learning environments, learning outcomes, learning and teaching activities, and student assessments might be designed, as outlined below.

\section{Guiding Principles for Critical Intercultural Practice}

Within the current and emerging contexts of global higher education, I suggest the three culturally relevant pedagogy principles set out above might be reframed for critical intercultural practice along the following lines:

- Students must experience academic success.

- Students must develop and/or maintain their cultural and intercultural competence.

- Students must develop a critical consciousness through which they challenge the status quo of current social orders locally and globally.

Each of these might be realized through meaningful, critical learning with and from and for culturally diverse others. Echoing Pope Francis' "culture of encounter" (see, for example CNA, 2013), gaining agency in and for a multicultural globalizing world requires knowing how self and others inhabit and are inhabited by the world we share.

\section{Practitioner Goals for Critical Intercultural Practice}

To achieve the three principles set out above, CIP practitioners have a need to:

- critique their own practice and the socio-cultural assumptions and values which it contains and projects; 
- respect and continuously seek to understand the cultures, capabilities, and aspirations of their diverse students and the diverse contexts in which they live;

- engage with students, peers, and communities locally and globally to develop practice which is equitable, relevant, and empowering.

Through approaches such as these, CIP practitioners situate themselves as reciprocal learners, committed to the individual and collective empowerment of themselves, their diverse students, and their diverse peers.

Table 1. Illustrative capabilities for graduates in a multicultural globalizing world.

\begin{tabular}{|c|c|}
\hline $\begin{array}{l}\text { How I identify my action } \\
\text { and disposition } \\
\text { capabilities }\end{array}$ & $\begin{array}{l}\text { Act-in-the-world } \\
\text { capabilities: } \\
\text { "I identify myself as being } \\
\text { the kind of person who is } \\
\text { able to: }\end{array}$ \\
\hline $\begin{array}{l}\text { Cross-cultural capability } \\
\text { Which enables a graduate } \\
\text { to work, enact their } \\
\text { discipline, and live their } \\
\text { life among diverse } \\
\text { cultural others }\end{array}$ & $\begin{array}{l}\text { - reflect upon my own cognitive, affective, and } \\
\text { behavioral responses to the ideas, behaviors, and } \\
\text { values of others; } \\
\text { modify my own communication in order to ensure } \\
\text { others understand and are understood; } \\
\text { - } \quad \text { take a mindful stance when engaging with others; } \\
\text { - accept that all cultural norms, including my own, } \\
\text { are arbitrary and susceptible to critique; } \\
\text { critique cultural norms from a respectful and } \\
\text { informed position. }\end{array}$ \\
\hline $\begin{array}{l}\text { Which enables a graduate } \\
\text { to see how their work, } \\
\text { discipline, and life } \\
\text { impacts upon the lives of } \\
\text { others. }\end{array}$ & $\begin{array}{l}\text { evaluate how an action might impact upon the } \\
\text { lives of others; } \\
\text { critique a policy or practice from the perspectives } \\
\text { of peoples in diverse contexts; } \\
\text { locate and draw upon alternative data sources to } \\
\text { gain a more complete understanding of an issue; } \\
\text { reflect upon how my own choices make } \\
\text { differences to the capabilities of others to lead } \\
\text { lives they have reason to value. }\end{array}$ \\
\hline
\end{tabular}

\section{Principal Outcomes of Critical Intercultural Practice}

Through the mainstream disciplinary curriculum and associated learning environments, experiences, and assessments, CIP sets out to develop and assess: 
- abilities to critique majority and minority, own and others', local and global perspectives upon disciplinary knowledge and its application;

- capabilities to successfully enact dialogue and interaction across social, cultural, and linguistic boundaries;

- $\quad$ agency to take personal and professional actions to enhance social justice for their own communities and those of others.

Much work has been done to identify the kinds of cross-cultural capabilities and global perspectives which students and graduates in a multicultural globalizing world might need. Table 1 (adapted from Killick, 2018, p. 54) presents one illustration of the kind of capabilities which are involved. CIP places such learning at the heart of the mainstream curriculum - embedded within disciplinary learning outcomes and then across assessments and learning experiences through the processes of critical alignment.

Capabilities such as these are not developed through encounters with the like-experienced and like-minded, nor within learning environments in which students of various minorities are ill-represented. It is through successful and meaningful encounters with diverse others within equitable learning spaces that the kind of dialogue and relationship building which enables students to advance and critique own and others' perspectives and priorities can be built.

\section{CIP in Practice}

As with critical pedagogy and culturally relevant pedagogy, CIP is not in itself proposed as a teaching method. Established student-centered approaches such as problem-based learning and collaborative learning may be appropriate ways to enact CIP, though for some learners and in some contexts, they may not. CIP does, though, require structural changes across the mainstream, disciplinary curriculum, involving all levels and types of practice to achieve the outcomes outlined above. How these applications manifest in practice is illustrated in Table 2. These applications are not discipline specific, and the ways in which they can be applied to practice will vary according to the contexts in which any discipline is being learned and the diversity of the learners who are engaging with it. 
Table 2. CIP outcomes applied to learning \& teaching practice.

\section{Outcome}

CIP sets out to develop and assess:

abilities to critique majority and

minority, own and others', local and global perspectives upon disciplinary

knowledge and its application;

capabilities to successfully enact

dialogue and interaction across social, cultural, and linguistic boundaries;

agency to take personal and professional actions to enhance social justice for their own communities and those of others;

\section{Application}

learning outcomes throughout a program explicitly build towards abilities associated with critiquing diverse perspectives;

diverse perspectives are represented throughout the curriculum;

students are enabled and positioned to bring their own perspectives into the curriculum;

assessments require students to critique diverse perspectives, including their own;

learning experiences are designed to build capabilities in identifying, comparing, and critiquing diverse perspectives and their sources.

learning outcomes throughout a programme explicitly build towards abilities associated with successful interaction with diverse others;

assessments require students to engage in dialogue and other forms of interaction with diverse others;

learning experiences are designed to incorporate significant engagement with peers and others from diverse sociocultural and linguistic boundaries (virtual and/or face-to-face);

learning outcomes throughout a program explicitly build towards abilities associated with self-efficacy and agency in professional and social contexts; issues of local and global social justice 
are represented throughout the curriculum;

assessments require students to develop and critique individual and group action plans to advance social justice in local and global contexts;

learning experiences are designed to incorporate engagement with communities and social justice issues of relevance to those communities.

\section{SUMMARY}

Where culturally relevant education is seen to represent "our best hope against" neoliberal education (Aronson \& Laughter, 2016, p. 164), critical intercultural practice, along the lines set out here, may extend that hope to the diverse students and contexts of the post-national university. CIP is proposed principally as an approach to practice which can build diverse student and graduate identities (self-in-the-world) and agency (act-in-theworld) to be and to act in a multicultural globalizing world. It represents the (re)assertion of a higher education which strives to develop learning and teaching practice which simultaneously:

- achieves greater equity in educational experiences and outcomes for all its students;

- engages with diversity as a valued resource for learning; and

- empowers all its students to act for social justice, locally and globally.

In each respect, it is of relevance across the emerging global higher education landscape, but perhaps most significantly for the post-national Anglophone western university. CIP may be achieved through a range of approaches and techniques consistent with current learning theory and best practice principles, and is underpinned by:

- educational principles concerning the centrality of the student as a cultural and intercultural being, who is to be empowered through the development of critical consciousness;

- the critical stance of the practitioner with regard to their own and others' cultures and ways of being, which informs a continuing 
effort to develop more equitable practice through reciprocal learning;

- key learning objectives concerning the critique of diverse perspectives, meaningful dialogue with diverse others and agency to enhance social justice locally and globally;

- applications in practice requiring structural changes throughout the mainstream curriculum at all levels of practice, including the design of learning outcomes, content, assessments, learning activities, and learning environments.

Learning and teaching practice can enhance or diminish student capabilities to realize a more global sense of self-in-the-world, along with the capabilities to act-in-the-world. CIP is proposed as an approach to practice to better meet both the needs of diverse students in diverse contexts and of a multicultural globalizing world, but structural change is needed also with regard to university governance, estates, quality assurance, and human resource functions if the messages they send through the hidden curriculum (Banks, 2001; Kentli, 2009) are to support rather than undermine those within the formal learning experience.

\section{REFERENCES}

ACE. (2015). International higher education partnerships: A global review of standards and practices. Washington, DC: American Council on Education.

Allport, G. (1979 [1954]). The nature of prejudice. Cambridge, MA: Perseus Books.

Ancis, J.R., Sedlacek, W.E, \& Mohr, J.J. (2000). Student perceptions of campus cultural climate by race. Journal of Counseling \& Development, 78(2), 180-185.

Aronson, B., \& Laughter, J. (2016). The theory and practice of culturally relevant education: A synthesis of research across content areas. Review of Educational Research, 86(1), 163-206.

Bailey, K.A. (2016). Racism within the Canadian university: Indigenous students' experiences. Ethnic and Racial Studies, 39(7), 1261-1279.

Bandura, A. (1977). Social learning theory. Englewood Cliffs, NJ: Prentice-Hall.

Banks, J.A. (2001). Cultural diversity and education: Foundations, curriculum, and teaching. Needham Heights, MA: Allyn and Bacon.

Berry, J., \& Loke, G. (2011). Improving the degree attainment of Black and minority ethnic students. London: Equality Challenge Unit/Higher Education Academy.

Biggs, J. (2003). Aligning teaching and assessing to course objectives. Paper presented at the Teaching and Learning in Higher Education: New Trends and Innovations, University of Aveiro, 13-17 April 2003. 
Bond, S.L. (2003). Untapped resources. Internationalization of the curriculum and classroom experience: A selected literature review. Ottawa: Canadian Bureau for International Education.

Bourke, B. (2010). Experiences of Black students in multiple cultural spaces at a predominantly White institution. Journal of Diversity in Higher Education, 3(2), 126-135.

Brown, S. (2005). Assessment for learning. Learning and Teaching in Higher Education, 1, 81-89.

Byrd, C.M. (2016). Does culturally relevant teaching work? An examination from student perspectives. SAGE Open, July-September 2016, 1-10.

Caruana, V, \& Ploner, J. (2010). Internationalisation and equality and diversity in higher education: merging identities. London: Equality Challenge Unit.

CNA. (2013). Pope Francis calls faithful to deeper encounters with others. Retrieved November 2017, from https:// www.catholicnewsagency. com/news/pope-francis-calls-faithful-to-deeper-encounters-with-others

Cole, D, \& Zhou, J. (2014). Diversity and collegiate experiences affecting self-perceived gains in critical thinking: Which works, and who benefits? The Journal of General Education, 63(1), 15-34.

Crenshaw, K.W. (1991). Mapping the margins: Intersectionality, identity, politics, and violence against women of color. Stanford Law Review, 43(6), 1241-1299.

Crisp, R.J, \& Turner, R.N. (2011). Cognitive adaptation to the experience of social and cultural diversity. Psychological Bulletin, 137(2), 242-266.

Curşeu, P.L, \& Pluut, H. (2011). Student groups as learning entities: The effect of group diversity and teamwork quality on groups' cognitive complexity. Studies in Higher Education, 38(1), 87-103.

de Wit, H, Gacel-Avila, J, Jones, E, \& Jooste, N (Eds.). (2017). The globalization of internationalization: Emerging voices and perspectives. London: Routledge.

Denson, N, \& Bowman, N. (2013). University diversity and preparation for a global society: The role of diversity in shaping intergroup attitudes and civic outcomes. Studies in Higher Education, 38(4), 555-570.

Denson, N, \& Zhang, S. (2010). The impact of student experiences with diversity on developing graduate attributes. Studies in Higher Education, 35, 529-543.

ECU. (2009). The experience of lesbian, gay, bisexual and trans staff and students in higher education. London: Equality Challenge Unit.

ECU. (2011). Joining up agendas: Internationalisation and equality and diversity in higher education. London: Equality Challange Unit.

ECU. (2013). Unconscious bias and higher education. London: ECU.

ECU. (2014). Equality in higher education: Statistical report 2014. Part 2: students. London: Equality Challenge Unit.

Edwards Jr., D.B. (2010). Critical pedagogy and democratic education: Possibilities for cross-pollination. Urban Review, 42, 221-242.

Fozdar, Farida, \& Volet, Simone. (2016). Cultural self-identification and orientations to cross-cultural mixing on an Australian university campus. Journal of Intercultural Studies, 37(1), 51-68. 
Freire, P. (1974). Education for critical consciousness. London: Bloomsbury.

Freire, P, \& Faundez, A. (1989). Learning to question: A pedagogy of liberation. New York: Continuum.

Freire, Paulo. (1970). Pedagogy of the oppressed. Harmondsworth: Penguin Education.

Gay, G. (2000). Culturally responsive teaching: Theory, research \& practice. New York: Teachers College Press.

Gilardi, S, \& Guglielmetti, C. (2011). University life of non-traditional students: Engagement styles and impact on attrition. The Journal of Higher Education, 82(1), 33-53.

Giroux, H.A. (2006). Academic freedom under fire: The case for critical pedagogy. College Literature, 33(4), 1-42.

HEFCE. (2015). Differences in employment outcomes: Equality and diversity characteristics. London: Higher Education Funding Council for England.

James, R. (2012). Social inclusion in a globalised higher education environment: The issue of equitable access to university in Australia. In T.N. Basit \& S. Tomlinson (Eds.), Social Inclusion and Higher Education (pp. 83-107). Bristol: Policy Press.

Jenkins, R. (2014). Social identity. Abingdon: Routledge.

Jones, E, \& Killick, D. (2013). Graduate attributes and the internationalised curriculum: Embedding a global outlook in disciplinary learning outcomes. Journal of Studies in International Education, 17(2), 165-182.

Kentli, F.D. (2009). Comparison of hidden curriculum theories. European Journal of Educational Studies, 1(2), 83-88.

Killick, D. (2017). Internationalization and diversity in higher education: Implications for teaching, learning and assessment. Houndsmill: Palgrave.

Killick, D. (2018). Developing intercultural practice: Academic development in a multicultural and globalizing World. Abingdon: Routledge.

Kincheloe, J.L. (2012). Critical pedagogy in the twenty-first century: Evolution for survival. Counterpoints, 422, 147-183.

Knight, J. (2016). Transnational education remodeled: Toward a common TNE framework and definitions. Journal of Studies in In International Education, 20(1), 34-47.

Knight, P (Ed.). (1995). Assessment for learning in higher education. Abingdon: RoutledgeFalmer.

Ladson-Billings, G. (1995a). But that's just good teaching! The case for culturally relevant pedagogy. Theory into Practice, 34(3), 159-165.

Ladson-Billings, G. (1995b). Toward a theory of culturally relevant pedagogy. American Educational Research Journal, 32(3), 465-491.

Land, S.M, Hannafin, M.J, \& Oliver, K. (2012). Student-centred learning environments: Foundations, assumptions and design. In D. Jonassen \& S. Land (Eds.), Theoretical foundations of learning environments (2nd ed., pp. 3-25). Abingdon: Routledge.

Lave, J., \& Wenger, E. (1998). Situated learning: Legitimate peripheral participation. Cambridge: Cambridge University Press. 
Leask, B. (2009). Using formal and informal curricula to improve interactions between home and international students. Journal of Studies in International Education, 13(2), 205-221.

Lewis, J.A, Neville, H.A, \& Spanierman, L.B. (2012). Examining the influence of campus diversity experiences and color-blind racial ideology on students' social justice attitudes. Journal of Student Affairs Research and Practice, 49(2), 119-136.

Loes, C, Pascarella, E, \& Umbach, P. (2012). Effects of diversity experiences on critical thinking skills: Who benefits? Journal of Higher Education, 83(1), 1-25.

Malouff, J.M, Stein, S.J, Bothma, L.N, Coulter, K, \& Emmerton, A. (2014). Preventing halo bias in grading the work of university students. Cognet Psychology, 1: 988937.

Marginson, S. (2007). Globalisation, the "idea of a university" and its ethical regimes. Higher Education Management and Policy, 19(1), 31-45.

McArthur, J. (2010). Achieving social justice within and through higher education: The challenge for critical pedagogy. Teaching in Higher Education, 15(5), 493504.

Mezirow, J. (1995). Transformation theory of adult learning. In M.R. Welton (Ed.), In defense of the lifeworld (pp. 39-70). New York: State University of New York Press.

Mukherji, B.R, Neuwirth, L.S, \& Limonic, L. (2017). Making the case for real diversity: Redefining underrepresented minority students in public universities. $S A G E$ Open, April-June 2017, 1-10.

NCES. (2010). Status and trends in the education of racial and ethnic groups. Washington, DC: National Center for Education Statistics.

NUS. (2011). Race for equality: A report on the experiences of Black students in further and higher education. London: National Union of Students.

Olson, C.L, Evans, R, \& Shoenberg, R.F. (2007). At home in the world: Bridging the gap between internationalization and multicultural education. Washington, DC: American Council on Education.

Oran, G. (2009). Preparing teachers for culturally relevant pedagogy. education.com. http://www.education.com/reference/article/culturally-relevant-pedagogy/

Pettigrew, T.F, \& Tropp, L.R. (2008). How does intergroup contact reduce prejudice? Meta-analytic tests of three mediators. European Journal of Social Psychology, 3, 922-934.

Smit, R. (2012). Towards a clearer understanding of student disadvantage in higher education: Problematising deficit thinking. Higher Education Research and Development, 31(3), 369-380.

Stevenson, J. (2012). Black and minority ethnic student degree retention and attainment. York: Higher Education Academy.

Tajfel, H, \& Turner, J.C. (1986). The social identity theory of intergroup behavior. In S. Worchel \& W.G. Austin (Eds.), Psychology of intergroup relations (pp. 3347). Chicago: Nelson-Hall. 
Turner, C.S. (2013). Advancing diversity in higher education. Journal of Diversity in Higher Education, 6(3), 155-157.

Volet, S.E., \& Ang, G. (2012). Culturally mixed groups on international campuses: An opportunity for inter-cultural learning. Higher Education Research \& Development, 31(1), 21-37.

Vygotsky, L.S. (1978). Mind in society: The development of higher psychological processes. Cambridge, MA: Harvard University Press.

Winkle-Wagner, R, \& Locks, A.M. (2014). Diversity and inclusion on campus. Abingdon: Routledge.

DAVID KILLICK, PhD, is Emeritus Fellow at Leeds Beckett University, UK. His major research interests lie in the areas of curriculum internationalization and inclusivity in higher education. Email: d.killick@leedsbeckett.ac.uk

Manuscript submitted: November 15, 2017

Manuscript revised: March 1, 2018 Accepted for publication: April 2, 2018 